\title{
Migraine: pharmacotherapy in the emergency department
}

\author{
Anne-Maree Kelly
}

\begin{abstract}
Migraine can be a disabling condition for the sufferer. For the small number of patients who fail home therapy and seek treatment in an emergency department, there are a number of therapeutic options. This paper reviews the evidence regarding the effectiveness and safety of the following therapies: the phenothiazines, lignocaine (lidocaine), ketorolac, the ergot alkaloids, metoclopramide, the "triptans", haloperidol, pethidine and magnesium. Based on available evidence, the most effective agents seem to be prochlorperazine, chlorpromazine and sumatriptan, each of which have achieved greater then $\mathbf{7 0 \%}$ efficacy in a number of studies.

(f Accid Emerg Med 2000;17:241-245)
\end{abstract}

Keywords: migraine

Migraine headache can be a disabling condition for the sufferer. The patient and their general practitioner successfully manage most migraine headaches. However, a small number fail to respond and sufferers may present for treatment at emergency departments (ED). As most patients have tried oral medications before attending the ED, other routes of administration (usually parenteral) are most often used in ED. This review will focus on the agents that may be used to treat migraine in $\mathrm{ED}$ and the evidence supporting their use.

\section{Definitions}

Most of the research in the area of migraine focuses on so called common migraine or migraine without aura. The Headache Classification Committee of the International Headache Society ${ }^{1}$ defines migraine without aura as an "idiopathic, recurring headache disorder manifesting in attacks lasting 4-72 hours. Typical characteristics are unilateral location, pulsating quality, moderate or severe intensity, aggravation by routine physical activity and association with nausea, photophobia and phonophobia." The rarer migraine with aura is described as an "idiopathic, recurring headache disorder manifesting with attacks of neurological symptoms unequivocally localisable to the cerebral cortex or brain stem, usually developing gradually over 5-20 minutes and lasting less than 60 minutes. Headache, nausea and/or photophobia usually follow neurological aura symptoms directly or after a free interval of less than an hour. The headache usually lasts less than 72 hours, but may be completely absent." At least two typical episodes are needed before this diagnosis can be assigned. In addition, there are a number of uncommon variants such as ophthalmoplegic and abdominal migraine.

\section{Pathophysiology}

The pathophysiology of migraine is complex and our understanding continues to evolve. Events implicated in migraine initiation include altered electrical activity ("cortical spreading depression"2), a failure of brain ion homeostasis, an efflux of excitatory amino acids from nerve cells and increased energy metabolism. ${ }^{3} \mathrm{~N}$-methyl-D-aspartate (NMDA) receptors are implicated in this process. ${ }^{3}$

The headache pain of migraine seems to result from the activation of the trigeminovascular system. ${ }^{4-6}$ The triggers to the development of migraine headache are probably chemical and are thought to originate in the brain, blood vessel walls and the blood itself. These triggers stimulate trigeminovascular axons causing pain and the release of vasoactive neuropeptides from perivascular axons. These neuropeptides act on mast cells, endothelial cells and platelets resulting in increased extracellular levels of arachidonate metabolites, amines, peptides and ions. These mediators and the resultant tissue injury lead to prolongation of pain and hyperalgesia. ${ }^{6}$

Serotonin has also been specifically implicated in migraine. By activation of afferents, it causes a retrograde release of substance $P$. This is turn increases capillary permeability and oedema. ${ }^{7}$ In addition, magnesium has been suggested as having a role. ${ }^{8}$

The complexity of the mechanisms involved in the genesis of migraine makes it likely that there are a number of ways to interrupt the processes to provide effective relief from migraine symptoms. A number of pharmacological agents and combinations of agents for the relief of migraine have been studied.

\section{Therapeutics}

Most patients who present to ED with severe migraine have tried to terminate their migraine headache with oral medication before their attendance. Therefore, this review will focus on the agents that are appropriate for use in ED. In considering them, the important issues to be considered are their efficacy, the need for additional medication and the incidence of "rebound" headache.

PROBLEMS WITH THE EVIDENCE

An evidence-based review of the therapeutics of acute migraine is compromised by the quality of the evidence available. With the exception of the drug company sponsored studies 
investigating the "triptans", most studies are small with less than 50 patients in each subgroup being the norm. This means that the power of these studies to reach methodologically sound conclusions is limited. In addition, a variety of measures of "success of treatment" are used by different study groups, which makes comparison difficult. Given these limitations, this paper attempts to pull together the available evidence to inform practice and form a basis for further research.

PHENOTHIAZINES: CHLORPROMAZINE AND PROCHLORPERAZINE

Phenothiazines are antipsychotic drugs. In the central nervous system, they are powerful antagonists of the neurotransmitter action of dopamine in the basal ganglia and limbic system. They are also potent anti-emetics via effects on the chemoreceptor trigger zone and neuroleptic actions seem to change pain perception. In addition, they are $\alpha$ adrenergic antagonists (which can lead to orthostatic hypotension); chlorpromazine having greater $\alpha$ blocking effect than prochlorperazine. And they have anti-cholinergic properties and are antagonists at both histamine and 5-HT receptors. ${ }^{9}$

Besides its hypotensive effect, the major side effect of phenothiazines in short-term use is dystonia. This is an idiosyncratic reaction and may occur after a single dose. ${ }^{9}$ The mechanism by which phenothiazines act in migraine is uncertain. It is possibly the result of a combination of actions: anti-5-HT effect, antidopamine effect in the chemoreceptor trigger zone and vascular effects via its $\alpha$ blocking action..$^{10}$

The evidence about chlorpromazine

Table 1 summarises the success rates with the use of chlorpromazine.

Dosing regimens have varied but a dose of $12.5 \mathrm{mg}$ intravenously (IV) repeated at 20 minute intervals to a total dose of $37.5 \mathrm{mg}$ would be representative. IV fluids need to be given because of the significant rate of orthostatic hypotension.

With respect to comparative trials, chlorpromazine has been reported to be superior to pethidine (one study), ${ }^{16}$ lignocaine (lidocaine) (one study) $)^{14}$ and dihydroergotamine (DHE) (one study) ${ }^{14}$ and of similar effectiveness to ketorolac (one study), ${ }^{17}$ metoclopramide (one study) ${ }^{18}$ and sumatriptan (one study). ${ }^{15}$

None of the trials have reported any cases of dystonia resulting from the use of chlorpromazine in this way.

Table 1 Success rates with the use of chlorpromazine for the treatment of migraine

\begin{tabular}{lllcl}
\hline Study & Year & Design & Patients (n) & Success rate (\%) \\
\hline Lane $e t ~ a l^{11}$ & 1985 & IV & 52 & 94 \\
Iserson $^{12}$ & 1983 & IM & 100 & 96 \\
McEwen $^{13}$ & 1987 & IM & 36 & 47 \\
Bell $e t ~ a l^{14}$ & 1990 & IV & $76(3$ arms) & 89 \\
Kelly $^{15}$ & 1997 & IV & 42 & 95 \\
\hline
\end{tabular}

The evidence about prochlorperazine

There are only a few small studies about prochlorperazine and migraine. Success rates of $67-92 \%{ }^{19-22}$ have been reported. Most studies use a dose of $10 \mathrm{mg} \mathrm{IV}$.

In comparative studies, prochlorperazine has been reported to give better pain relief than sumatriptan (one study), ${ }^{22}$ metoclopramide (two studies) ${ }^{2021}$ and ketorolac (one study). ${ }^{23}$

A preliminary report regarding the use of rectal prochlorperazine suppositories reported good outcomes ${ }^{24}$ but its design makes evaluation difficult.

ERGOT ALKALOIDS

The pharmacological activity of ergot alkaloids derives from their ability to interact to varying degrees with subtypes of adrenergic, dopaminergic and tryptaminergic receptors. ${ }^{9}$ The ergot alkaloids have a number of side effects related to their pharmacological actions. These include peripheral vasoconstriction, peripheral gangrene, vomiting, nausea, chest pain, pruritis and headache. ${ }^{9}$

The ergot alkaloids seem to exert their antimigraine effect by strongly binding to $5-\mathrm{HT}$ (Subtype 1B and 1D) receptors in the blood vessels of the dura and scalp resulting in inhibition of the trigeminal nerve mediated neurogenic inflammation. ${ }^{625} 26$

The evidence regarding $\mathrm{DHE}$

Studies of DHE, either alone or in combination with metoclopramide or hydroxyzine, report success rates of $23 \%,{ }^{14} 73 \%{ }^{27}$ and $93 \%{ }^{28}$ when used in the dose of $1 \mathrm{mg}$ IV.

In comparative studies, DHE has been shown to be more effective than pethidine (one study) ${ }^{28}$ or lignocaine (one study), ${ }^{14}$ less effective than chlorpromazine (one study) ${ }^{14}$ and of similar effectiveness to sumatriptan (one study) $)^{27}$ and pethidine (one study). ${ }^{29}$

Of particular note, in the only study where adverse events were carefully collected, $55 \%$ of patients treated with DHE experienced severe gastrointestinal side effects. ${ }^{14}$

Nasal sprays of DHE are also available. Headache relief rates of $27 \%$ at 30 minutes and $70 \%$ at four hours have been reported. ${ }^{30}$ One study suggests DHE spray to be less effective than sumatriptan subcutaneous (SC). ${ }^{31}$

HALOPERIDOL

Haloperidol is a butyrophenone, heterocyclic antipsychotic agent. It has effects on the chemoreceptor trigger zone reducing nausea and vomiting. It is an antagonist of the central effects of dopamine and is relatively selective for the D2 dopamine receptor. It is also a moderate $\alpha$ antagonist peripherally and has anti5-HT effects. It is less sedating than chlorpromazine and results in less orthostatic hypotension. Dystonic reactions are haloperidol's principal side effect. ${ }^{9}$ It is postulated that haloperidol is effective in migraine because of its anti-dopamine and/or anti 5-HT effects.

The evidence regarding haloperidol

No controlled or comparative trials of the use of haloperidol in migraine have been pub- 
lished. Recently, a case series of six cases of migraine treated with $5 \mathrm{mg}$ of haloperidol IV after a 500 to $1000 \mathrm{ml}$ bolus of IV fluids reported complete or substantial relief within 25 to 65 minutes. Side effects were reported as "minimal". ${ }^{32}$

KETOROLAC

Ketorolac is a non-steroidal anti-inflammatory agent (NSAID) that inhibits prostaglandin synthesis, platelet aggregation and serotonin release from platelets. ${ }^{9}$ It is thought that NSAIDs may act in migraine by reducing the role of prostaglandins in increasing the sensitivity of blood vessel walls to pain and in regulating smooth muscle tone and reactivity as well as decreasing changes in vascular permeability. ${ }^{33}$

The evidence about ketorolac

The doses used in studies have been $30-60 \mathrm{mg}$ intramuscularly (IM). The reported success rate is $60 \% .^{33}$

In comparative studies, ketorolac (at a dose of $60 \mathrm{mg}$ ) has been reported to be similar in effectiveness to pethidine (two studies) ${ }^{33} 34$ but at a dose of $30 \mathrm{mg}$ IM was less effective than pethidine (one study). ${ }^{35}$ Ketorolac has been reported to be less effective than prochlorperazine (one study). ${ }^{23}$ A very small study compared ketorolac $60 \mathrm{mg}$ IM with chlorpromazine $25 \mathrm{mg}$ IV and found no difference in efficacy between the agents at two hours. ${ }^{17}$ However, important methodological problems make the value of this study questionable.

LIGNOCAINE

Lignocaine is a class $1 \mathrm{~b}$ anti-arrhythmic agent (membrane stabiliser) used for the treatment of ventricular arrhythmia. It is also a potent local anaesthetic agent. ${ }^{9}$ It was hypothesised that lignocaine might act in migraine by its membrane stabilising effect inhibiting the release of vasoactive substances from platelets thus inhibiting the sterile inflammatory response. ${ }^{14}$

The evidence about lignocaine

The usual dose used in reported studies is of the order of $100 \mathrm{mg}$. A randomised, prospective, double blind trial comparing IV lignocaine $(1 \mathrm{mg} / \mathrm{kg})$ with placebo failed to demonstrate a difference between the two for the relief of the head pain of migraine. ${ }^{36}$ In comparative studies lignocaine has been shown to be less effective than chlorpromazine (one study) ${ }^{14}$ and DHE (one study). ${ }^{14}$

Recently, nasal lignocaine spray at a concentration of $4 \%$ has been trialled. A success rate of $55 \%$ has been reported however the early relapse rate was $42 \%{ }^{37}$

METOCLOPRAMIDE

Metoclopramide is a non-phenothiazine central dopamine antagonist and a peripheral muscarinic agonist. It increases gastric emptying and is anti-emetic at the chemoreceptor trigger zone. ${ }^{9}$ It is postulated that metoclopramide acts in migraine by anti-emetic effects combined with central anti-dopamine effects. ${ }^{38}$
Side effects of metoclopramide include drowsiness and dystonia. ${ }^{9}$

\section{The evidence regarding metoclopramide}

Uncontrolled studies have reported successful relief of migraine with metoclopramide of $75 \% .{ }^{39}$ In a placebo controlled trail, metoclopramide $10 \mathrm{mg}$ orally was found not to be superior to placebo in the relief of headache pain from migraine. ${ }^{40}$ However, studies of IV metoclopramide report benefit over placebo $^{38}{ }^{41}$ and in one a success rate of $67 \% .^{38}$

In comparative studies, metoclopramide in a dose of $10 \mathrm{mg}$ IM or IV has been reported to be less effective than prochlorperazine (two studies)..$^{20}$ High dose metoclopramide (0.1 $\mathrm{mg} / \mathrm{kg} / \mathrm{dose}$ IV to a total of three doses; average dose $16 \mathrm{mg}$ ) was found to be of similar effectiveness to chlorpromazine (one study). ${ }^{18}$

PETHIDINE

Pethidine is a synthetic narcotic analgesic that exerts its pharmacological activity principally by binding to opioid receptors. The main side effects of pethidine are nausea and vomiting, respiratory depression, drowsiness and smooth muscle spasm, particularly in the biliary tree. ${ }^{9}$ A major concern with the use of pethidine is the possibility of the development of dependence. ${ }^{9}$ This concern is supported by the findings of a study of 1900 sufferers of chronic headache, which found that $5 \%$ were narcotic abusers. ${ }^{42}$

It has been hypothesised that opioids are incapable of providing lasting, effective analgesia in migraine as they depend for their effect on serotonergic projections and patients suffering migraine have been shown to have central nervous system serotonin depletion. ${ }^{43}$

The evidence with respect to pethidine The usual dose of pethidine is $75 \mathrm{mg} \mathrm{IM} / \mathrm{IV}$. A literature search covering the years 1976-1997 failed to identify any placebo controlled studies of the effectiveness of pethidine for the relief of migraine headache. Clinical success rates of $22 \%$ and $50 \%$ have been reported. ${ }^{1628}$

In comparative trials pethidine, either alone or in combination with hydroxyzine and dimenhydramine, has been reported to be less effective than DHE (one study) ${ }^{28}$ and chlorpromazine (one study) ${ }^{16}$ and of similar effectiveness to DHE (one study). ${ }^{29}$ With respect to ketorolac, pethidine was found to give better migraine relief than ketorolac in a dose of 30 mg IM ( 1 study) ${ }^{35}$ but when the ketorolac dose was $60 \mathrm{mg}$ IM the agents had similar effectiveness (two studies)..$^{33}$

SUMATRIPTAN AND OTHER "TRIPTANS"

Sumatriptan is a specific and selective 5-HT (subtype 1D) agonist that has no effect on other 5-HT receptor subtypes. This receptor is found predominantly in cranial blood vessels and produces constriction of large blood vessels that may be dilated during episodes of migraine. ${ }^{44}$ Sumatriptan may be administered orally, SC or by nasal spray. Adverse effects include drowsiness, weakness, dizziness, flushing, rash, pruritis, increase in blood pressure, 
chest pain or chest tightness. Importantly, sumatriptan is contraindicated in patients with a history of ischaemic heart disease, uncontrolled hypertension or the concomitant use of ergot preparations. There are also a significant number of non-responders for which no clinical, pharmacokinetic or genetic explanation has been found. ${ }^{45}$

The anti-migraine effect of sumatriptan is thought to be attributable to its effect on the 5 -HT subtype $1 \mathrm{D}$ receptors in cranial blood vessels. ${ }^{25}$ Sumatriptan and ergot alkaloids block neurogenic inflammation by acting at pre-junctional 5-HT receptors on trigeminovascular fibres. ${ }^{6}$

The evidence regarding "the triptans"

Three large double blind studies have compared the efficacy of sumatriptan in doses of either $6 \mathrm{mg}$ or $8 \mathrm{mg}$ subcutaneously with placebo. Clinical success rates were $70 \%,{ }^{46}$ $75-80 \%{ }^{47}$ and $70 \%{ }^{48}$ respectively. In each study about half the sumatriptan treated group reported mild adverse effects including injection site reactions, nausea, flushing and chest heaviness. Thirty four to 60 per cent of patients successfully treated with sumatriptan reported recurrent headache within 24 hours. $^{47}$

In comparative studies, sumatriptan when compared with DHE IV had a significantly higher rate of relief of headache at two hours, but there was no difference in rate of relief at three or four hours. ${ }^{27}$ Sumatriptan has reported to be more effective than DHE nasal spray. ${ }^{31} \mathrm{It}$ has also been reported to be of similar effectiveness to chlorpromazine (one study) ${ }^{15}$ and less effective than prochlorperazine (one study).22 Sumatriptan treated patients reported a significantly higher rate of headache recurrence within 24 hours.

Newer "triptans" such as rizatriptan (10 mg orally) have reported success rates of the order of $75-80 \%{ }^{49}$

Sumatriptan is also now available as a nasal spray $(20 \mathrm{mg})$ and has a reported clinical success rate of $63-78 \% .^{50} 51$

\section{MAGNESIUM}

In migraine patients, magnesium has been shown to play an important part as a regulator of neuronal excitability and therefore hypothetically of headache. ${ }^{52}$ Magnesium concentrations may also have effects on serotonin receptors, NMDA receptors and nitric oxide synthesis and release. ${ }^{53}$ Evidence suggests that about $50 \%$ of migraine sufferers have reduced concentrations of ionised magnesium. ${ }^{53}$

\section{The evidence about magnesium}

A preliminary study reports clinical success in 35 of 40 patients after infusion of $1 \mathrm{~g}$ of magnesium sulphate. ${ }^{54}$ Response was more likely in those with low ionised magnesium concentrations.

\section{Summary}

Review of the evidence has some clear implications for the management of migraine in ED. Lignocaine fails to reach acceptable efficacy standards and as such is not recommended for use in acute migraine. Haloperidol and magnesium need to be studied in appropriate trials before conclusions can be drawn. Ketorolac, metoclopramide and pethidine perform a little better but each has been shown to be inferior to other treatments. The potential for dependence and abuse must also be considered with pethidine. The data on DHE are difficult to interpret because it is often used in combination with other agents, for example, metoclopramide, however it also has been shown to be less effective than chlorpromazine and sumatriptan in acute treatment and has a high rate of unpleasant side effects. At this time, the most effective agents seem to be prochlorperazine, chlorpromazine and sumatriptan, each of which have achieved greater then $70 \%$ efficacy in a number of studies.

1 Headache Classification Committee of the International Headache Society. Classification and diagnostic criteria for headache disorders, cranial neuralgias and facial pain. Cephalgia 1988; 8 (suppl 7):1-96.

2 Zagami AS. Pathophysiology of migraine and tension-type headache. Curr Opin Neurol 1994;7:272-7.

3 Lauritzen M. Pathophysiology of the migraine aura. The spreading depression theory. Brain 1994;117:199-210.

4 Cailliett R. Pain: mechanisms and management. Philedelphia: FA Davis, 1993.

5 Goadsby PJ, Edvinsson L. The trigeminovascular system and migraine: studies characterising cerebrovascular and neuropeptide changes seen in humans and cats. Ann Neurol 1993;33:48-56.

6 Moskowitz MA. Neurogenic inflammation $\mathrm{n}$ the pathophysiology and treatment of migraine. Neurology 1993;43 (suppl 3):16-20

7 Vanmhoutte PM, Cohen RA, Van Neueten JM. Serotonin and the arterial vessels. F Cardiovasc Pharmacol 1984;6 (suppl 2):422-8.

8 Mauskop A, Altura BT, Cracco RQ, et al. Intravenous magnesium sulphate rapidly alleviates headaches of various types. Headache 1996;36:154-60.

9 Gilman AG, Rall TW, Nies AS, et al. The pharmacological Gilman AG, Rall TW, Nies AS, et al. The pharmacological
basis of therapeutics. 8th ed. New York: McGraw-Hill, basis 1991.

10 Lance JW. The pathophysiology of migraine: A tentative synthesis. Pathol Biol (Paris) 1992;40:355-60.

11 Lane PL, Ross R. Intravenous chlorpromazine: preliminary results in acute migraine. Headache 1985;25:302-4.

2 Iserson KV. Parenteral chlorpromazine treatment in migraine. Ann Emerg Med 1983;12:756-8.

13 McEwen JI, O'Connor HM, Dinsdale HB. Treatment of migraine with intramuscular chlorpromazine. Ann Emerg Med 1987;16:758-63.

14 Bell R, Montoya D, Shuaib A, et al. A comparative trial of three agents in the treatment of acute migraine headache. Ann Emerg Med 1990;19:1079-82.

15 Kelly AM, Ardagh M, Curry C, et al. Intravenous chlorpromazine versus intramuscular sumatriptan for acute mi-

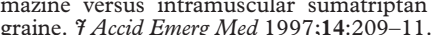

16 Lane PL, McLellan BA, Baggoley CJ. Comparative efficacy of chlorpromazine and meperidine with dimenhydramine in migraine headache. Ann Emerg Med 1989;18:360-5.

17 Shrestha M, Singh R, Moreden J, et al. Ketorolac versus chlorpromazine in the treatment of acute migraine without aura: A prospective randomised double-blind trail. Arch Int Med 1996;156:1725-8

18 Cameron JD, Lane PL, Speechley M. Intravenous chlorpromazine versus intravenous metoclopramide in acute migraine headache. Ann Emerg Med 1995;2:597-602.

19 Jones J, Sklar D, Dougherty J, et al. Randomised, double-blind trial of IV prochlorperazine for the treatment of acute headache. $\mathscr{F} A M A$ 1989;261:1174-6.

20 Jones J, Pack S, Chun E. Intramuscular prochlorperazine versus metoclopramide as single-agent therapy for the versus metoclopramide as single-agent therapy for the
treatment of acute migraine headache. Am $\mathcal{F}$ Emerg Med 1996;14:262-4.

21 Coppola M, Yealy DM, Leibold RA. Randomised, placebocontrolled evaluation of prochlorperazine versus metoclopramide for emergency department treatment of migraine headache. Ann Emerg Med 1995;26:541-6.

22 Donohue C, Thomas SH, Benson N, et al. Prochlorperazine versus sumatriptan for the emergency department therapy of migraine. [Abstract]. Ann Emerg Med 1995;25:154-5.

23 Seim MB, March JA, Dunn KA. Intravenous ketorolac versus intravenous prochlorperazine for the treatment of migraine headache. Acad Emerg Med 1998;5:573-6.

24 Jones EB, Gonzalez ER, Boggs JG, et al. Safety and efficacy of rectal prochlorperazine for the treatment of migraine in the emergency department. Ann Emerg Med 1994;24:23741 .

25 Buzzi MG, Moskowitz MA. Evidence for 5-HT-1B / 1D receptors mediating antimigraine effect of sumatriptan and dihydroergotamine. Cephalgia 1991;11:165-8. 
26 Saxena PR, Den-Boer MO. Pharmacology of anti-migraine drugs. I Neurol 1991;238 (suppl 1):28-35.

27 Winner P, Ricalde O, Le Force B, al A double-blind study of subcutaneous dihydroergotamine versus subcutaneous sumatriptan in the treatment of acute migraine. Arch Neurol 1996;53:180-4.

28 Klappen JA, Stanton J. Current emergency treatment of severe migraine headaches. Headache 1993;33:560-2

29 Carleton SC, Shesser RF, Pietrzak MP, et al. Double-blind, multicentre trial to compare the efficacy of intramuscular dihydroergotamine plus hydroxyzine versus intramuscular meperidine plus hydroxyzine for the emergency department treatment of acute migraine headache. Ann Emerg Med 1998;32:129-38.

30 Gallagher RM. Acute treatment of migraine with dihydroergotamine nasal spray: Dihydroergotamine Working Group. Arch Neurol 1996;53:1285-91.

31 Touchon J, Bertin L, Pilgrim AJ, et al. a comparison of subcutaneous sumatriptan and dihydroergotamine nasal spray in the acute treatment of migraine. Neurology 1996;47:361in

32 Fisher H. A new approach to emergency department therapy of migraine headache with IV haloperidol. f Emerg

33 Duarte C, Dunaway F, Turner L, et al. Ketorolac versus meperidine and hydroxyzine in the treatment of acute migraine headache: A randomised, prospective, doubleblind trial. Ann Emerg Med 1992;21:1116-21.

34 Davis CP, Torre PR, Williams C, et al. Ketorolac versus meperidine-plus-promethazine treatment of migraine headache: evaluation by patients. Am 7 Emerg Med 1995;13:146-50

35 Larkin GL, Prescott JE. A randomised, double-blind, comparative study of the efficacy of ketorolac tromethamine versus meperidine in the treatment of severe migraine. Ann Emerg Med 1992;21:919-24.

36 Reutens DC, Fatovich DM, Stewart-Wynne EG, et al. IV lignocaine clinically effective in acute migraine? Cephalgia 1991;11:245-7.

37 Maizels M, Scott B, Cohen W, et al. Intranasal lidocaine for treatment of migraine: A randomised, double-blind, treatment of migraine: A randomise

38 Tek DS, McClellen DS, Olshaker JS, et al. A prospective, double-blind study of metoclopramide hydrochloride for the control of migraine in the emergency department. Ann Emerg Med 1990;19:1083-7.

39 Hughes JB. Metoclopramide in migraine treatment. Med $f$ Aust 1977;2:580.
40 Tokola RI, Kangasniemi P, Neuvonen PJ, et al. Tolfenamic acid, metoclopramide, caffeine and their combinations in he treatment of migraine headaches. Cephalgia 1984;4: 253-63.

41 Ellis GL, Delaney J, DeHart DA, et al. The efficacy of metoclopramide in the treatment of migraine headache. Ann Emerg Med 1993;22:191-5.

42 Granella F, Farina S, Malferrari G, et al. Drug abuse in chronic headache: A clinico-epidemiologic study. Cephalgia 1987;7:15-19.

43 Edmeads J. Emergency management of headache. Headache 1988;28:677.

44 Abramowicz M. Sumatriptan for migraine. Medical Letter 1992;34:91-3.

45 Schoenen J. Acute migraine therapy: The newer drugs. $\mathcal{F}$ Neurol 1997;10:237-43.

46 Cady RK, Wendt JK, Kirchner JR, et al. Treatment of acute migraine with subcutaneous sumatriptan. FAMA 1991; 265:2831-5

47 The Subcutaneous Sumatriptan International Study Group. Treatment of migraine attacks with sumatriptan. $N$ Engl f Med 1991;325:316-21.

48 Akpunonu BE, Mutgi AB, Federman DJ, et al. Subcutaneous sumatriptan for the treatment of acute migraine in patients admitted to the emergency department: A multicenter study. Ann Emerg Med 1995;25:464-9.

49 Kramer MS, Matzura-Wolfe D, Polis A, et al. A placebocontrolled crossover study of rizatriptan in the treatment of multiple migraine attacks. Rizatriptan Multiple Attack Study Group. Neurology 1998;51:773-81.

50 Ryan R, Elkind A, Baker CC, et al. Sumatriptan nasal spray for the acute treatment of migraine. Results of two clinical studies. Neurology 1997;49:1225-30.

51 Salonen R, Ashford E, Dahlof C, et al. Intranasal sumatriptan for the acute treatment of migraine. International Intranasal Sumatriptan Study Group. F Neurol 1994;241:463-9.

52 Mazzotta G, Sarchielli P, Alberti A, et al. Electromyographical ischemic test and intracellular magnesium concentration in migraine and tension-type headache patients. Headache 1996;36:357-61.

53 Mauskop A, Altura BM. Role of magnesium in the pathogenesis and treatment of migraines. Clin Neurosci 1998;5:24-7.

54 Mauskop A, Altura BT, Cracco RQ, et al. Intravenous magnesium sulfate rapidly alleviates headaches of various types. Headache 1996:36:154-60. 